\title{
A PRODUCTION MODEL FOR A FLEXIBLE PRODUCTION SYSTEM AND PRODUCTS WITH SHORT SELLING SEASON
}

\author{
MOUTAZ KHOUJA AND ABRAHAM MEHREZ
}

Received 12 June 2004

We address a practical problem faced by many firms. The problem is deciding on the production levels for a product that has a very short selling season. The firm has a full period to produce and meet a lumpy demand which occurs at the end of the period. The product is no longer demanded after the end of the period. A constant production rate which minimizes average unit cost may increase holding costs. Varying the production rate at discrete points in time may increase production costs but may also decrease holding costs. In addition, allowing changes in the production rate enables the incorporation of forecast revisions into the production plan. Therefore, the best production plan depends on the flexibility of the production system and on the holding cost. In this paper, we formulate and solve a model of this production planning problem. Two models are developed to deal with two types of the average unit cost function. Numerical examples are used to illustrate the results of the model.

\section{Introduction}

Consider the problem faced by a firm which produces a product for a full period to meet a demand which is concentrated at the end of that period. There is no demand for the product after the end of the period. This problem is common for many suppliers of products treated in the single period model [8]. However, unlike retailers, suppliers are not faced with the problem of discounting the product if any inventory remains at the end of the period [15], because they produce to the orders of the retailers. The problem for the suppliers is deciding on the production levels of products. A constant production rate which minimizes average unit cost may increase holding costs. Varying the production rate at discrete points in time may increase production costs but may also decrease holding costs. Therefore, the best production plan depends on the flexibility of the production system and on the holding cost. In addition, allowing changes in the production rate enables the incorporation of forecast revisions into the production plan.

The cost of producing at different production rates depends on the volume flexibility of the production system. Volume flexibility is defined as the ability of a system to operate profitably at different output levels [13]. The cost of producing at different production 
rates has two components. The first component is the cost of switching from one production rate to another, and the second is the penalty cost of deviating from the production rate which minimizes average unit cost. The switching cost arises from the need to change the size of the work force by hiring and laying off workers [6]. As for the penalty cost, stability of production costs over varying production volumes has been suggested as a measure of volume flexibility [3]. Ramasesh and Jayakumar [11] used the shape of the average unit cost curve to measure volume flexibility. Flat average unit cost curve indicates a volume flexible production system. Average unit cost initially decreases because fixed costs are spread over more units. At higher volumes, increases in tool wearout $[2,12]$ and increases in error rates cause average unit cost to increase. The treatment of production rates as decision variables has been incorporated in many inventory models $[4,7,10,14]$.

Several authors have developed production planning models which allow the incorporation of forecast revisions into the production plan $[1,9]$. Bitran et al. [1] dealt with a system that produces several families of style goods. A family is defined as a set of items consuming the same amount of resources and sharing the same setup. Bitran et al. assumed that the setup cost associated with changeover from one family to the next is large enough that managers attempt to produce each family once in the planning horizon. Also, the authors assumed that the mean demand for each family is invariant over the horizon whereas item demands are forecasted in each period. Demand occurs in the last season of the horizon and demand estimates for items are revised every period. The problem is finding item production quantities which will maximize the expected profit. Bitran et al. assumed the demand of items in a family follow a joint normal distribution and that each period has limited production capacity. The problem was formulated as a stochastic mixed integer programming problem and by exploiting its hierarchical structure (families and then items), the authors formulated and solved a deterministic mixed integer programming problem which provided an approximate solution. Matsuo [9] observed that a limitation of Bitran et al's model [1] is that it included discrete production periods and each family is assigned to exactly one period which works well only if the number of families is much larger than the number of periods. Also, the complexity of Bitran et al's method made sensitivity analysis difficult. To avoid the limitations of Bitran et al's model, Matsuo used a continuous treatment of time and formulated the problem as a two-stage stochastic sequencing model. In stage I, a sequence of production quantities of families is determined at the beginning of planning horizon. In stage II, the production quantities of items in each family are determined using the revised demand forecast. Matsuo [9] developed and tested a heuristic procedure for solving the problem. Both of the above models dealt with constant production rate and constant unit production cost.

In this paper, we formulate and solve two production planning models. In the first model, the firm incurs a linear penalty cost for deviating from the minimum average unit cost production rate whereas in the second model it incurs a quadratic penalty cost. In Section 2, we introduce the basic model in which a single production rate change is allowed during the period and solve the linear and then the quadratic penalty case. In Section 3, we allow revisions to the demand forecast and multiple production rates for the linear penalty case. We close with a discussion and suggestion for future research in Section 4 . 


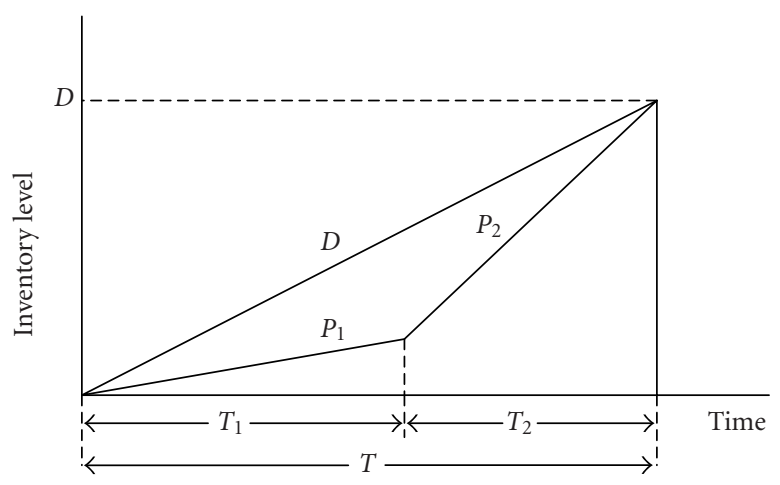

Figure 2.1. Two production plans to meet lumpy demand.

\section{Model I: single production rate change}

Consider a firm which has a very short selling season relative to the total production period. Management must design a production plan to meet the forecasted lumpy demand at the end of the period. Demand for the product exists only in the current period. A production plan specifies production rates during the period. We initially restrict the number of possible production rates to two, which implies at most one production rate change.

Figure 2.1 shows two possible production plans. The first plan is to produce at a constant rate of $D$ for the total duration of the period $T$. The second plan is to produce at a rate of $P_{1}$ during $T_{1}$ and then increase the production rate to $P_{2}$ during $T_{2}$. The two plans incur different holding and production costs. The problem is analyzed under the following assumptions:

(1) demand is concentrated at the end of the period,

(2) holding cost is linear in the number of units held,

(3) the cost of changing production rates increases linearly in the difference between the rates,

(4) average unit cost as a function of the output rate is convex with a minimum at $P_{0}$.

Assumption 2 is commonly used in inventory management. The cost of changing production rates in assumption 3 has been justified in the production planning literature [6]. The convexity of the average unit cost in assumption 4 is well accepted in the production literature [11].

Define the following notation:

$T_{1}=$ duration with a production rate of $P_{1}$,

$P_{1}=$ production rate during the first part of the cycle $\left(T_{1}\right)$,

$T_{2}=$ duration with a production rate of $P_{2}$,

$P_{2}=$ production rate during the second part of the cycle $\left(T_{2}\right)$,

$C_{0}=$ the minimum average unit cost (i.e., the average unit cost at the design volume),

$P_{0}=$ the design volume of the production system (i.e., the volume which minimizes average unit cost), 


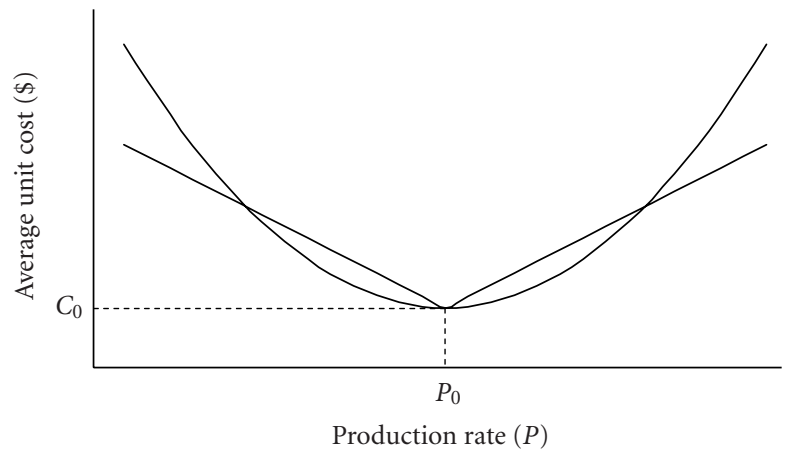

Figure 2.2. Two cases of the average unit cost.

$R=$ annual holding cost as a percentage of inventory value,

$C_{1}=$ average unit cost at production rate $P_{1}$,

$C_{2}=$ average unit cost at production rate $P_{2}$, and

$f\left(P_{1}, P_{2}\right)=$ the cost of switching from a production rate of $P_{1}$ to $P_{2}$,

$D=$ demand at the end of the period.

If the average unit cost is symmetric around the minimum, then optimal solutions must satisfy $P_{1} \leq P_{0} \leq P_{2}$. Otherwise, reducing $P_{1}$ to $P_{0}$ and increasing $P_{2}$ to $P_{0}$ will reduce the holding cost, production cost, and production rate switching cost. We assume that the demand is a random variable with a minimum $D_{L}$, a mean $D_{\mu}$, and maximum $D_{M}$ and that the capacity of the production system is sufficient to produce at the minimum average unit cost for the maximum demand, $D_{M} \leq P_{0}$.

We assume $C_{1}$ is a convex decreasing function in $P_{1}$ and $C_{2}$ is a convex increasing function in $P_{2}$. Linear and quadratic symmetrical cases of $C_{1}$ and $C_{2}$ are shown in Figure 2.2. We also assume $f\left(P_{1}, P_{2}\right)$ depends only on the absolute difference $\left|P_{1}-P_{2}\right|$. The total annual cost is

$$
T C=\frac{1}{2} R C_{1} T_{1}^{2} P_{1}+R C_{1} T_{1} T_{2} P_{1}+\frac{1}{2} R C_{2} T_{2}^{2} P_{2}+C_{1} T_{1} P_{1}+C_{2} T_{2} P_{2}+f\left(P_{1}, P_{2}\right),
$$

where

$$
\begin{gathered}
T_{1}+T_{2}=T, \\
P_{1} T_{1}+P_{2} T_{2}=D .
\end{gathered}
$$

Without loss of generality, we assume $T=1$. Equation (2.2) becomes

$$
T_{1}+T_{2}=1
$$

Lemma 2.1 shows that to minimize total cost, the production rate must be reduced or kept at $D$ in the first part of the period to avoid large holding cost. A reduction is likely to be optimal if the holding cost is high and the system is volume flexible, which implies that deviations from the minimum cost production rate do not incur large penalty. 
The next two sections provide solutions for the linear and quadratic penalty cases. Let the superscript * denote optimality.

Lemma 2.1. The optimal solution to minimizing TC satisfies $P_{1}^{*} \leq D$ and $P_{2}^{*} \geq D$.

Proof. See appendix.

2.1. The linear penalty cost case. In this case, deviations from the minimum average unit cost production rate results in the same linear penalty in either direction as shown in Figure 2.2. The average unit cost during $T_{1}$ and $T_{2}$ are

$$
\begin{aligned}
& C_{1}=C_{0}+a\left|P_{1}-P_{0}\right|, \\
& C_{2}=C_{0}+a\left|P_{2}-P_{0}\right|,
\end{aligned}
$$

respectively. Also, the switching cost is linear and is given by

$$
f\left(P_{1}, P_{2}\right)=K\left|P_{1}-P_{2}\right|
$$

where $K$ is the penalty cost for changing the production rate by one unit.

Equations (2.4)-(2.7) are used to eliminate $C_{1}, C_{2}, P_{2}, T_{2}$, and $f\left(P_{1}, P_{2}\right)$ from TC. Also, since we focus on systems for which $P_{2}^{*} \geq P_{0}$ or $P_{2}^{*}=D$, we eliminate the absolute value operator. Simplifying TC gives:

$$
\begin{aligned}
T C=[ & a D\left(4 P_{1}-2 P_{0}+D R-P_{0} R\right)+2 P_{1}(K-a) \\
& -2\left[K+a\left(D-P_{1}\right)\right]\left(D-P_{1}\right) /\left(T_{1}-1\right) \\
& +a\left[P_{0}\left(4 P_{1}+D R+3 P_{1} R\right)-2 P_{1}\left(2 P_{1}+\left(D+P_{1}\right) R\right)\right] T_{1} \\
& \left.-2 a\left(P_{0}-P_{1}\right) P_{1} R T_{1}^{2}+C_{0}\left[P_{1} R T_{1}+D\left(2+R-R T_{1}\right)\right]\right] / 2 .
\end{aligned}
$$

Define

$$
T_{1 C}=\frac{1+R-\sqrt{1+R}}{R}
$$

Lemma 2.2. TC is concave in $P_{1}$ for $T_{1} \in\left(0, T_{1 C}\right)$ and convex for $T_{1} \in\left(T_{1 C}, 1\right]$.

Proof. See appendix.

For any $T_{1} \in\left[0, T_{1 C}\right)$, by Lemmas 2.1 and 2.2 , the optimal $P_{1}$ is $P_{1}=0$ or $P_{1}=D$. The later case is the constant production rate solution. Substituting $P_{1}=0$ into (2.9) and differentiating $T C$ twice with respect to $T_{1}$ gives

$$
\frac{\partial^{2} T C}{\partial T_{1}^{2}}=\frac{2 D(K+a D)}{\left(1-T_{1}\right)^{3}}>0 .
$$


Thus, $T C$ is convex in $T_{1}$ for $P_{1}=0$. The necessary condition for $T_{1}$ to be optimal is obtained from setting $\partial T C / \partial T_{1}=0$, which gives:

$$
T_{1 r}=1-\sqrt{\frac{2(K+a D)}{R\left(C_{0}-a P_{0}\right)}} .
$$

Obviously, the optimal $T_{1 r}$ must satisfy $0<T_{1 r} \leq 1$. By inspection, $T_{1 r}$ in (2.11) satisfies $T_{1 r} \leq 1$. If $T_{1 r}>0$ then $P_{1}=0$ and $T_{1}=T_{1 r}$ are local minima and a comparison between $T C\left(P_{1}=0\right)$ and $T C\left(P_{1}=D\right)$ is needed. If $T_{1 r}<0$ or $T_{1 r}=0$ then $P_{1}=P_{2}=D$ is optimal.

An examination of the expression of $T_{1 r}$ provides some useful insights into the model:

(1) $T_{1 r}$ is increasing in $R$ which implies that for large holding cost, it is optimal to delay production for a long duration of time to avoid the large cost of holding inventory. Following the same argument, for small holding cost, $T_{1 r}<0$ and it is optimal to start producing immediately.

(2) For large cost of switching the production level by one unit, $K, T_{1 r}<0$ and it is optimal not to have a change in the production rate from the previous period or during the period.

(3) The smaller the value of the penalty parameter $a$ (which implies a more flexible system), the longer the optimal $T_{1 r}$. Since the penalty of deviating from the minimum average unit cost production rate is small, it is beneficial to reduce the holding cost by producing at a large production rate at the end of the period. Under extreme conditions when $a \approx 0$ and $K \approx 0$ (the system is completely flexible), $T_{1 r} \approx 1$ and all the production is concentrated at the end of the period.

Example 2.3. Consider a firm with the following data: $P_{0}=110000$ units/year, $D=$ 100000 units/year, $C_{0}=\$ 50, R=0.15, K=0.05$, and $a=0.00001$. If the firm follows a constant production rate strategy of $P_{1}=P_{2}=D$ then $T C=\$ 5371328$ per year. Using the proposed model gives $P_{1}^{*}=0, T_{1}^{*}=0.4649$ years, $P_{2}^{*}=186892$ units/year, $T_{2}^{*}=$ 0.5351 years, and $T C=\$ 5289973$ per year which represents a saving of $\$ 81355$ per year over the constant production rate plan. For a higher holding cost of $R=0.30$, the model yields $P_{1}^{*}=0, T_{1}^{*}=0.6216$ years, $P_{2}^{*}=264305$ units/year, $T_{2}^{*}=0.3784$ years, and $T C=\$ 5460040$ per year which represents a saving of $\$ 285799$ per year over the constant production rate strategy which has a $T C=\$ 5745839$ per year. In cases where the holding cost is low and/or the switching cost is high, the constant production rate strategy is optimal. For example, if $R=0.10$ and $K=\$ 2$ then $P_{1}^{*}=P_{2}^{*}=D$.

2.2. The quadratic penalty cost case. In this case, deviations from the design production rate yield symmetric quadratic penalty in either direction (see Figure 2.2). The average unit cost during $T_{1}$ and $T_{2}$ are

$$
\begin{aligned}
& C_{1}=C_{0}+a\left(P_{1}-P_{0}\right)^{2}, \\
& C_{2}=C_{0}+a\left(P_{2}-P_{0}\right)^{2},
\end{aligned}
$$


respectively. Equations (2.4), (2.5), (2.8), (2.12), and (2.13) are used to eliminate $C_{1}, C_{2}$, $P_{2}, T_{2}$, and $f\left(P_{1}, P_{2}\right)$ from $T C$ and then setting $\partial T C / \partial P_{1}=0$ gives the necessary conditions for $P_{1}$ to be optimal as

$$
P_{1}=\frac{-x \pm \sqrt{x^{2}-4 y W}}{2 y}
$$

where

$$
\begin{aligned}
x= & 2 a T_{1}\left(4 P_{0}\left(1+R\left(1-T_{1}\right)\right)\left(T_{1}-1\right)+3 D T_{1}\left(2+R\left(1-T_{1}\right)\right)\right), \\
y= & 3 a T_{1}\left(2-4 T_{1}-R\left(1-T_{1}\right)\left(3 T_{1}-2\right)\right), \\
W= & a\left(-3 D^{2}\left(2+R\left(1-T_{1}\right)\right)-4 D P_{0}\left(2+R\left(1-T_{1}\right)\right)\left(1-T_{1}\right)+R P_{0}^{2}\left(T_{1}-1\right)^{2}\right) \\
& +\left(2 K+C_{0} R\left(T_{1}-1\right)\right)\left(T_{1}-1\right) T_{1} .
\end{aligned}
$$

Our analysis shows that $\left(-x+\sqrt{x^{2}-4 y W}\right) / 2 y$ is the positive root. Therefore, $P_{1,1}=$ $\left(-x+\sqrt{x^{2}-4 y W}\right) / 2 y$ is substituted into (2.1) and a one-dimensional search is conducted to find $T_{1}^{*}$. Since no proof of convexity in $T_{1}$ can be obtained for this case, we can only claim a local minimum. $T_{1}^{*}$ is then substituted in (2.14) and by Lemma 2.1 if $P_{1,1}>D$, then $P_{1}^{*}=D$, whereas if $P_{1,1}<0$, then $P_{1}^{*}=0$. If $P_{1}^{*} \neq D$ then the total cost of producing at a constant production rate $T C\left(P_{1}=P_{2}=D\right)$ must be compared to the local minimum of $T C\left(P_{1}^{*}, T_{1}^{*}\right)$.

Example 2.4. We use the same data as in Example 2.3 with a quadratic average unit cost function for which $a=2 \times 10^{-9}$. If the firm follows a constant production rate strategy of $P_{1}=P_{2}=D$, then $T C=\$ 5401500$ per year. Using the proposed model gives $P_{1}^{*}=0$, $T_{1}^{*}=0.14085$ years, $P_{2}^{*}=116394$ units/year, $T_{2}^{*}=0.85915$ years, and $T C=\$ 5336700$ per year, which represents a saving of $\$ 64800$ per year. For a less flexible system with $K=\$ 10$, the constant production rate strategy $P_{1}=P_{2}=100000$ with a cost of $T C=$ $\$ 6396500$ is optimal.

\section{Model II: forecast revisions and multiple production rates}

We now treat demand as a random variable whose probability density function can be forecasted by management. Obviously, the forecasts improve as the selling season draws closer and production decisions must be revised accordingly. We analyze only the linear penalty case. Let

$D_{N}=$ the largest demand for which $P_{1}=0$ is optimal.

Because of forecast revisions, we no longer set $T=1$. For any $T,(2.11)$ becomes

$$
T_{1 r}=T-\sqrt{\frac{2(K+a D)}{R\left(C_{0}-a P_{0}\right)}} .
$$




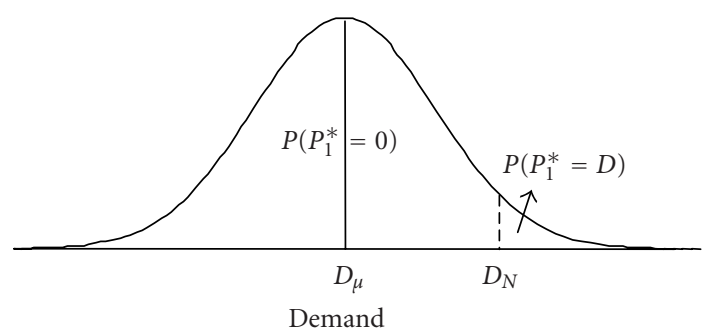

Figure 3.1. Probability density function of demand.

From (3.1), $D_{N}$ is given by setting $T_{1 r}=0$ (otherwise $T_{1}^{*}<0$ ) which gives

$$
D_{N}=\frac{-2 K+\left(C_{0}-a P_{0}\right) R T^{2}}{2 a}
$$

For any value of demand satisfying $D<D_{N}, P_{1}^{*}=0$, and for any value satisfying, $D>$ $D_{N}, P_{1}^{*}=D$ (see Lemma 2.1). Therefore, the probabilities of the different values of $P_{1}^{*}$ being optimal are as shown in Figure 3.1. Let $I_{i}$ be the beginning inventory at time of forecast revision $i$. The following procedure is designed to optimize the production plan at each forecast revision.

\section{Production planning procedure}

Step 0 . Set $T=1, i=0$, and $I_{0}=0$.

Step 1. Forecast the demand distribution.

Set $D_{L}=D_{L}-I_{i}, D_{M}=D_{M}-I_{i}$, and $D_{\mu}=D_{\mu}-I_{i}$.

Step 2. Compute $D_{N}$ using (3.2).

Step 3. Compute $P\left(P_{1}^{*}=0\right)=P\left(D<D_{N}\right)$ and $P\left(P_{1}^{*}=D\right)=1-P\left(D<D_{N}\right)$.

Step 4. If $P\left(P_{1}^{*}=0\right)>P\left(P_{1}^{*}=D\right)$ then set $P_{1}^{*}=0$, find $T_{1}^{*}$ using $(3.1)$, and find $T_{2}^{*}$ and $P_{2}^{*}$ using $(2.2)$ and (2.3), respectively.

If $P\left(P_{1}^{*}=0\right)<P\left(P_{1}^{*}=D\right)$ and then set $P_{2}^{*}=D_{\mu} / T$.

Step 5. If no more forecast updates are to be made, execute the plan.

If more forecast updates are to be made at time $T_{i+1}$, then

Set $i=i+1, T=T-T_{i}, I_{i}=I_{i-1}+\max \left\{\left(T_{i}-T_{i-1}-T_{1}^{*}\right), 0\right\} P_{2}^{*}$ and go to Step 1.

Example 3.1. Consider a problem with $a=0.000022, K=0.1$, and the rest of the parameters as given in Example 2.3. Suppose the firm starts at time zero (i.e., the beginning of the period) with a forecast of a uniformly distributed demand with the parameters shown in Table 3.1. This forecast is updated at four points in time as shown in Table 3.1. Using (3.2) yields $D_{N}=158000$ which results in $P\left(P_{1}^{*}=0\right)=1$ and $T_{1}^{*}=0.2225$ but since the forecast is revised at $0.2, T_{1}^{*}=0.20$. After 0.2 periods, $D_{N}=99250$ which results in $P\left(P_{1}^{*}=0\right)=0.5625$ and $T_{1}^{*}=0.00489$. Therefore, production starts at $0.2+0.00489=$ 0.20489 at $P_{2}^{*}=123245$ units/period. The forecast is updated at $0.4,0.6$, and 0.8 periods and new production rates are established according to the proposed procedure as shown in Table 3.1 . 
Table 3.1. Production plan with 4 forecast revisions.

\begin{tabular}{|c|c|c|c|c|c|c|c|c|c|c|c|c|c|c|c|}
\hline$i$ & $T_{i}$ & $T$ & $D_{L}$ & $D_{M}$ & $D_{\mu}$ & $I_{i}$ & $D_{L}-I_{i}$ & $D_{M}-I_{i}$ & $D_{\mu}-I_{i}$ & $D_{N}$ & $T_{1}^{*}$ & $P_{1}^{*}$ & $P\left(P_{1}^{*}=0\right)$ & $T_{2}^{*}$ & $P_{2}^{*}$ \\
\hline 0 & 0 & 1 & 80000 & 107000 & 93500 & 0 & 80000 & 107000 & 93500 & 158000 & 0.2225 & 0 & 1 & 0.7775 & 120262 \\
\hline 1 & 0.2 & 0.8 & 88000 & 108000 & 98000 & 0 & 88000 & 108000 & 98000 & 99250 & 0.00489 & 0 & 0.5625 & 0.7951 & 123254 \\
\hline 2 & 0.4 & 0.6 & 87000 & 106000 & 96500 & 24048 & 62952 & 81952 & 72452 & 53848 & - & 120753 & 0 & 0.4000 & 120753 \\
\hline 3 & 0.6 & 0.4 & 90000 & 105000 & 97500 & 48199 & 41801 & 56801 & 49301 & 21407 & - & 123253 & 0 & 0.2000 & 123253 \\
\hline 4 & 0.8 & 0.2 & 97000 & 97000 & 97000 & 72849 & 24151 & 24151 & 24151 & & - & 120753 & 0 & 0.0000 & 120753 \\
\hline & 1 & 0 & & & & 97000 & & & & & & & & & \\
\hline
\end{tabular}

Table 3.2. A reactive production plan to forecast revisions.

\begin{tabular}{|c|c|c|c|c|c|c|c|}
\hline \multicolumn{2}{|c|}{ Time } & \multirow{2}{*}{$\begin{array}{l}\text { Production } \\
\text { rate } \\
\text { (units/period) }\end{array}$} & \multirow{2}{*}{$\begin{array}{l}\text { Unit } \\
\text { cost } \\
\text { (\$/unit) }\end{array}$} & \multirow{2}{*}{$\begin{array}{l}\text { Production } \\
\text { cost } \\
\text { (\$) }\end{array}$} & \multirow{2}{*}{$\begin{array}{l}\text { Holding cost for } \\
\text { current units } \\
\text { (\$) }\end{array}$} & \multirow{2}{*}{$\begin{array}{l}\text { Holding cost } \\
\text { for previous } \\
\text { production } \\
\qquad \$(\$)\end{array}$} & \multirow{2}{*}{$\begin{array}{l}\text { Production rate } \\
\text { change cost } \\
\text { (\$) }\end{array}$} \\
\hline From & To & & & & & & \\
\hline 0.000 & 0.200 & 93500 & 50.36 & 941788 & 14127 & 113015 & 9350 \\
\hline 0.200 & 0.400 & 99125 & 50.24 & 995993 & 14940 & 89639 & 563 \\
\hline 0.400 & 0.600 & 96625 & 50.29 & 971936 & 14579 & 58316 & 250 \\
\hline 0.600 & 0.800 & 99125 & 50.24 & 995993 & 14940 & 29880 & 250 \\
\hline \multirow[t]{2}{*}{0.800} & 1.000 & 96625 & 50.29 & 971936 & 14579 & 0 & 250 \\
\hline & & & & 4877647 & 73165 & 290850 & 10663 \\
\hline
\end{tabular}

Table 3.3. A production plan based on the proposed model.

\begin{tabular}{cccccccc}
\hline Time & & $\begin{array}{l}\text { Production } \\
\text { rate }\end{array}$ & $\begin{array}{l}\text { Unit } \\
\text { cost }\end{array}$ & $\begin{array}{l}\text { Production } \\
\text { cost }\end{array}$ & $\begin{array}{l}\text { Holding cost for } \\
\text { current units }\end{array}$ & $\begin{array}{l}\text { Holding cost } \\
\text { for previous } \\
\text { production }\end{array}$ & $\begin{array}{l}\text { Production rate } \\
\text { change cost }\end{array}$ \\
From & To & (units/period) & $(\$ /$ unit $)$ & $(\$)$ & $(\$)$ & $(\$)$ & 0 \\
\hline 0.000 & 0.205 & 0 & 52.42 & 0 & 0 & 0 & 0 \\
0.205 & 0.400 & 123254 & 50.29 & 1209411 & 17698 & 36282 & 250 \\
0.400 & 0.600 & 120753 & 50.24 & 1213247 & 18199 & 72680 & 250 \\
0.600 & 0.800 & 123253 & 50.29 & 1239721 & 18596 & 109871 & 250 \\
0.800 & 1.000 & 120753 & 50.24 & 1213247 & 18199 & 218833 & 13075 \\
\hline
\end{tabular}

Tables 3.2 and 3.3 provide a comparison between a plan in which the production rate is set to meet the mean demand at a constant production rate at each forecast revision, and one which follows the suggested model, respectively. The implementation of the proposed model results in reducing the total cost from \$5 252324 to \$5 180226 , a saving of $1.4 \%$

\section{Conclusions and suggestions for future research}

This paper addresses the problem of deciding on the production levels for a product which has a very short selling season. The firm has a full period to produce and meet a lumpy demand which occurs at the end of the period. The best production plan depends on the flexibility of the production system and on the holding cost. Two models for dealing with linear and quadratic penalty functions for deviating from the minimum average unit cost production rate are developed. The models allow only a single production rate 


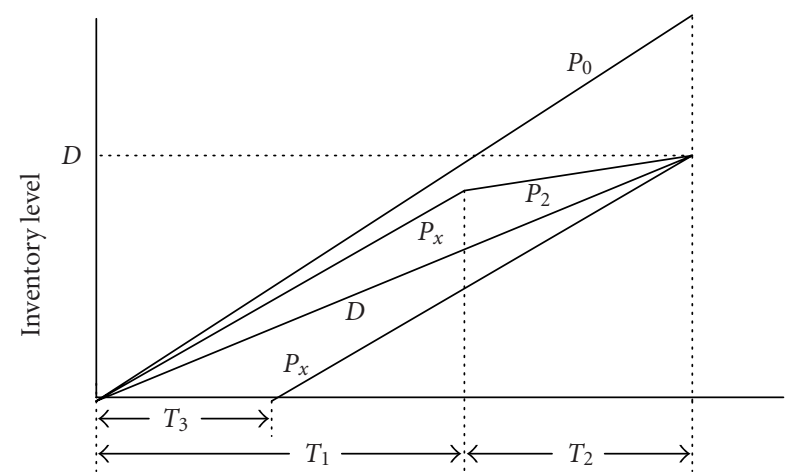

Figure 4.1. Inventory level.

change. The model is extended to allow revisions to the demand forecast and multiple production rates for the linear penalty case.

Future research involve dealing with multi-item problem. In this case, the problem will also involve a scheduling aspect. For this scheduling aspect, to reduce holding cost, it may be best to produce items that are costly to hold and require short processing time at the end of the period and items with long processing time and low holding cost early in the period. A similar strategy was found to be optimal in the economic delivery and scheduling problem (ELDSP) [5].

\section{Appendix}

Proof of Lemma 2.1. Suppose $P_{1}=P_{x}$, where $D<P_{x} \leq P_{0}$ during $T_{1}$, then $P_{2}<D$ during $T_{2}$. Using Figure 4.1, the following observations are made with regard to the total cost components.

(1) Production costs. The same amount of production at a lower unit production cost can be achieved by setting $P_{1}=0$ during $T_{3}$ and $P_{2}=P_{x}$ during $\left(1-T_{3}\right)$ can be achieved.

(2) Holding costs. The cumulative inventory at any time is lower for $P_{1}=0$ during $T_{3}$ and $P_{2}=P_{x}$ during $\left(1-T_{3}\right)$ than $P_{1}=P_{x}$. Also, the production cost of this inventory is lower. Therefore, the holding cost is lower for $P_{1}=0$ during $T_{3}$.

(3) Switching costs. The switching cost for the $P_{1}=P_{x}$ plan is $K\left[P_{x}+\left(P_{x}-D\right) / T_{2}\right]$ whereas for the $P_{1}=0$ during $T_{3}$ plan it is $K P_{x}$. Therefore, the switching cost for the $P_{1}=P_{x}$ plan is larger by $K\left(P_{x}-D\right) / T_{2}$.

From observations (1)-(3), the total cost for $P_{1}=P_{x}$ is greater than the total cost for $P_{1}=0$ during $T_{3}$. Therefore, $P_{1}=P_{x}>D$ cannot be optimal.

Proof of Lemma 2.2. The first derivative of TC with respect to $P_{1}$

$$
\begin{aligned}
\frac{\partial T C}{\partial P_{1}}= & \frac{K+2 a\left(D-P_{1}\right)}{\left(T_{1}-1\right)}+a\left[2 D-2 P_{1}-\left(P_{0}-2 P_{1}\right) R T_{1}^{2}\right] \\
& +\left[C_{0} R+a\left[P_{0}(4+3 R)-2\left(D R+2 P_{1}(2+R)\right)\right] R_{1}\right] / 2
\end{aligned}
$$


and the second derivative

$$
\frac{\partial^{2} T C}{\partial P_{1}^{2}}=\frac{2 a\left(1+R\left(T_{1}-1\right)^{2}-2 T_{1}\right) T_{1}}{T_{1}-1} .
$$

$\partial^{2} T C / \partial P_{1}^{2}=0$ at $T_{11}=0, T_{12}=(1+R-\sqrt{1+R}) / R$, and $T_{13}=(1+R+\sqrt{1+R}) / R$. Since $(1+R-\sqrt{1+R}) / R>0$ and $1+(1-\sqrt{1+R}) / R<1,0 \leq T_{12}<1$. Also, $T_{13} \geq 1$. For $T_{11}<T_{1}<T_{12}, \partial^{2} T C / \partial P_{1}^{2}<0$ and $T C$ is concave, and for $T_{12}<T_{1}<T_{13}, \partial^{2} T C / \partial P_{1}^{2}<0$ and $T C$ is convex.

\section{References}

[1] G. R. Bitran, E. A. Haas, and H. Matsuo, Production planning of style goods with high setup costs and forecast revisions, Oper. Res. 34 (1986), no. 2, 226-236.

[2] T. J. Drozda and C. Wick (eds.), Tool and Manufacturing Engineers Handbook, Vol. 1: Machining, Society of Manufacturing Engineers, Michigan, 1983.

[3] C. H. Falkner, Flexibility in manufacturing plants, Proceedings of 2nd ORSA/TIMS Conference on Flexible Manufacturing Systems (Michigan, 1986), Elsevier, New York, 1986.

[4] G. Gallego, Reduced production rates in the economic lot scheduling problem, Int. J. Prod. Res. 31 (1993), no. 5, 1035-1046.

[5] J. Hahm and C. A. Yano, The economic lot and delivery scheduling problem: the common cycle case, IIE Transactions 27 (1995), no. 2, 113-125.

[6] A. C. Hax and D. Candea, Production and Inventory Management, Prentice-Hall, New Jersey, 1984.

[7] M. Khouja, The scheduling of economic lot sizes on volume flexible production systems, Int. J. Prod. Econ. 48 (1996), no. 1, 73-86.

[8] ( The single-period (news-vendor) problem: literature review and suggestions for future research, Omega 27 (1999), no. 5, 537-553.

[9] H. Matsuo, A stochastic sequencing problem for style goods with forecast revisions and hierarchical structure, Management Sci. 36 (1990), no. 3, 332-347.

[10] I. Moon, G. Gallego, and D. Simchi-Levi, Controllable production rates in a family production context, Int. J. Prod. Res. 29 (1991), no. 12, 2459-2470.

[11] R. V. Ramasesh and M. D. Jayakumar, Measurement of manufacturing flexibility: a value-based approach, J. Oper. Manage. 10 (1991), no. 4, 446-467.

[12] P. J. Schweitzer and A. Seidmann, Optimizing processing rates for flexible manufacturing systems, Management Sci. 37 (1991), no. 4, 454-466.

[13] A. K. Sethi and S. P. Sethi, Flexibility in manufacturing: a survey, Int. J. Flex. Manufact. Syst. 2 (1990), no. 4, 289-328.

[14] E. A. Silver, Deliberately slowing down output in a family production context, Int. J. Prod. Res. 28 (1990), no. 1, 17-27.

[15] E. A. Silver, D. F. Pyke, and R. P. Peterson, Inventory Management and Production Planning and Scheduling, 3rd ed., John Wiley \& Sons, New York, 1998.

[16] N. Slack, The flexibility of manufacturing systems, Int. J. Oper. Product. Manage. 7 (1987), no. 4, $35-45$.

Moutaz Khouja: The University of North Carolina at Charlotte, Charlotte, NC 28223, USA

E-mail address: mjkhouja@email.uncc.edu

Abraham Mehrez: Ben-Gurion University of the Negev, Beer Sheva 84105, Israel 


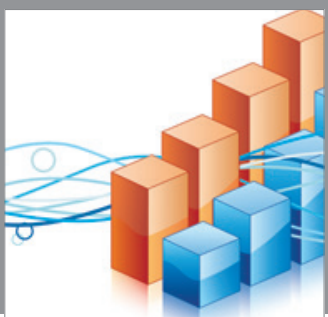

Advances in

Operations Research

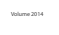

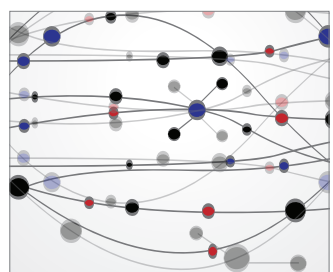

\section{The Scientific} World Journal
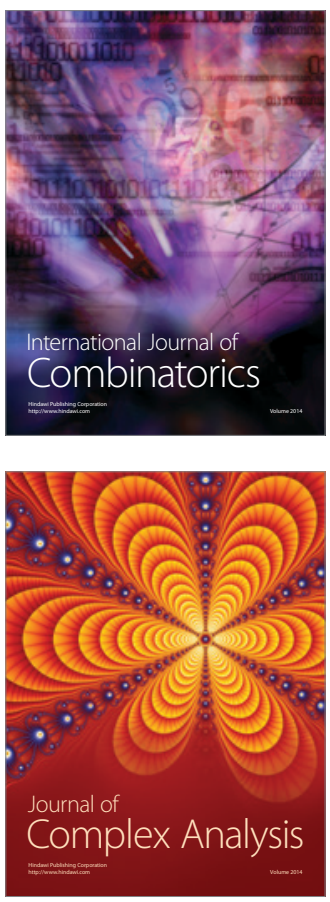

International Journal of

Mathematics and

Mathematical

Sciences
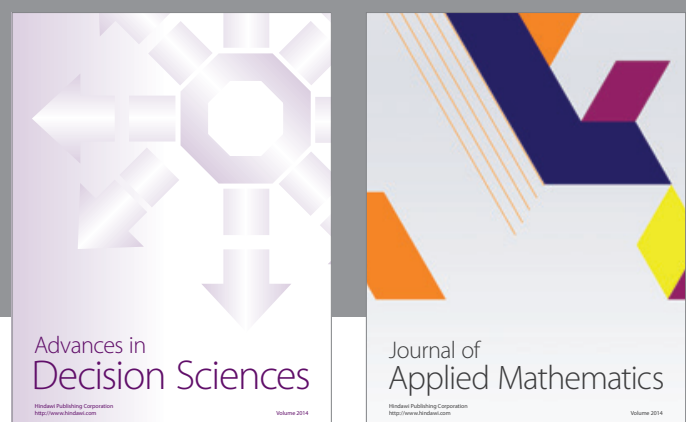

Journal of

Applied Mathematics
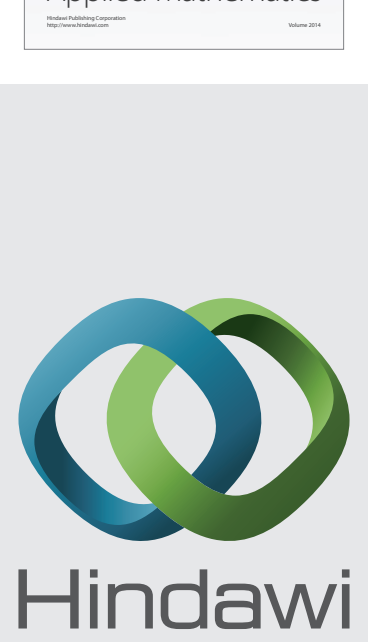

Submit your manuscripts at http://www.hindawi.com
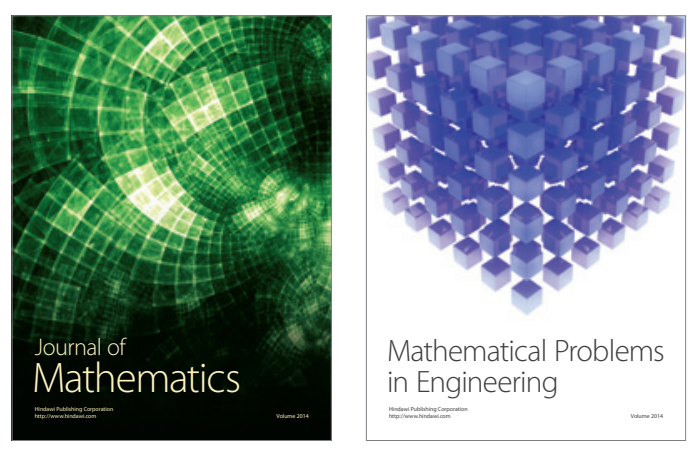

Mathematical Problems in Engineering
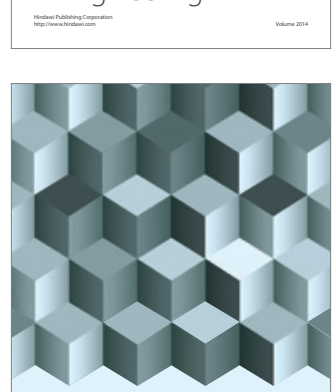

Journal of

Function Spaces
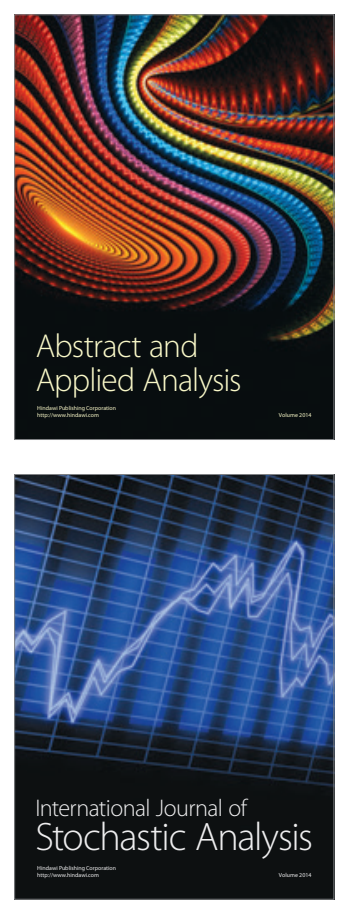

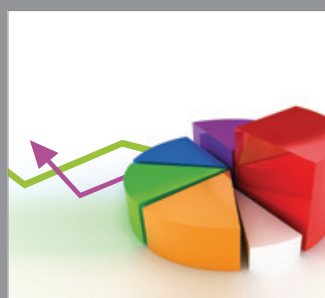

ournal of

Probability and Statistics

Promensencen
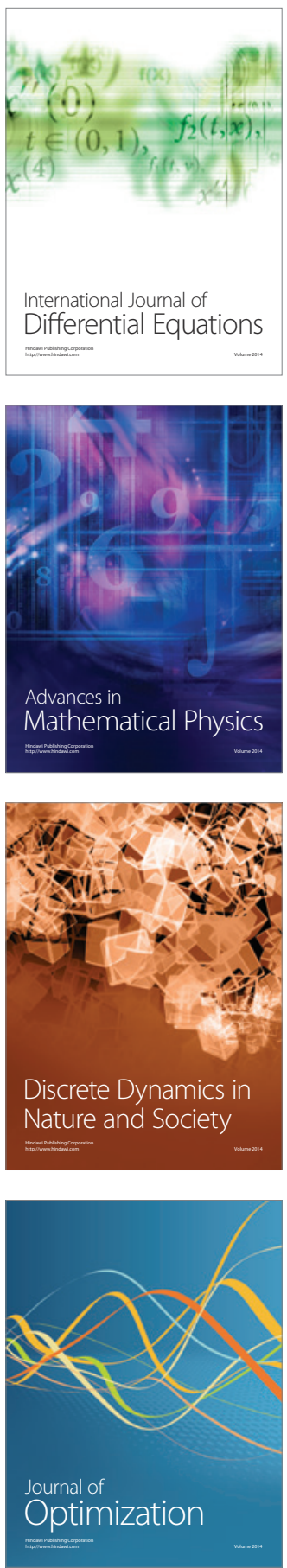